\title{
Sororreatividade para Brucella abortus em rebanho caprino no estado do Rio de Janeiro, Brasil: relato de caso
}

\author{
Seroreactivity for Brucella abortus in a goat herd \\ in Rio de Janeiro, Brazil: case report
}

\author{
Renato Varges, ${ }^{*}$ Luciana Medeiros, ${ }^{*}$ Walter Lilenbaum*
}

\begin{abstract}
Resumo
A brucelose caprina por Brucella melitensis nunca foi relatada no Brasil, enquanto poucos relatos de infecção por Brucella abortus foram feitos. Um rebanho caprino composto de 124 animais adultos localizado no estado do Rio de Janeiro foi avaliado quanto à presença de anticorpos anti-Brucella abortus. Sete $(5,6 \%)$ caprinos e uma vaca presente na propriedade apresentaram sororeatividade. Todos os animais sororreativos foram abatidos. Doze meses após os primeiros testes todos os animais do rebanho foram novamente testados e todos os animais foram negativos.
\end{abstract}

Palavras-chave: Brucella abortus, brucelose, caprinos.

\begin{abstract}
Caprine brucellosis caused by Brucella melitensis, has never been related in Brazil, while Brucella abortus infection is sporadically related. A goat herd with 124 adult animals located in Rio de Janeiro, Brazil was tested against anti-Brucella abortus antibodies. Seven (5.6\%) goats and one cow were seroreactive and were slaughtered. Twelve month after the first screening the whole herd was tested and all the animals were negative.
\end{abstract}

Keywords: Brucella abortus, brucellosis, goats.

A caprinocultura é uma atividade econômica em franco crescimento no Brasil. Apesar de o rebanho nacional contar com cerca de 12 milhões de cabeças, a produtividade leiteira destes animais ainda é muito baixa (Lilenbaum et al., 2007). Entre outros fatores, as doenças infecciosas, em especial àquelas da esfera reprodutiva, contribuem para esta baixa produtividade.

A brucelose em caprinos é caracterizada por abortamento no terço final da gestação, queda na fertilidade, natimortalidade e diminuição na produtividade leiteira, alterações relatadas em rebanhos caprinos de outros estados brasileiros (Alves et al., 1997).

O principal agente da brucelose em caprinos é a espécie Brucella melitensis, que não ocorre no Brasil (Poester et al., 2002). No entanto, infecções esporádicas por Brucella abortus, que tem no gado bovino seu principal hospedeiro, podem ocorrer em outras espécies, como no homem, eqüinos, caninos e em diversos ruminantes, como ovinos, caprinos, bubalinos e camelídeos, além de ruminantes selvagens, quando estes acidentalmente entram em contato com o agente de origem bovina (Radostits et al., 2000; Ribeiro et al., 2003; Megid et al., 2007). Esta infecção pode representar uma fonte importante de perdas econômicas para os produtores (Poester et al., 2002). O objetivo deste trabalho foi relatar a sororreatividade para B.abortus em uma propriedade de caprinos de produção leiteira localizada no estado do Rio de Janeiro.

Avaliou-se um rebanho caprino, abaixo descrito, quanto à presença de anticorpos anti-Brucella abortus. O rebanho foi acompanhado e 12 meses após a realização dos primeiros testes e adoção de medidas de controle, todos os animais do rebanho foram novamente testados. Cento e vinte e quatro caprinos adultos, da raça Saanen, de um criatório com bom manejo reprodutivo e nutricional, com controle permanente de artrite-encefalite caprina e de leptospirose e localizado na Região Serrana do estado do Rio de Janeiro foram estudados. Nesta propriedade havia três vacas que eram utilizadas como fonte de leite para o aleitamento dos cabritos.

Colheu-se sangue para obtenção de soro de 124 caprinos adultos e três vacas da propriedade. Após centrifugação, as amostras foram testadas seguindo as recomendações internacionais (Alton et al., 1988; Office International des Epizooties, 2004) e de acordo com as normas do Ministério da Agricultura, Pecuária e Abastecimento (Brasil, 2004). Desta forma, foram utilizadas as provas do antígeno acidificado tamponado (AAT) corado pelo Rosa Bengala como método de triagem e a prova do 2-mercaptoetanol (2-ME) como teste confirmatório.

* Universidade Federal Fluminense, Laboratório de Bacteriologia Veterinária, Instituto Biomédico, Departamento de Microbiologia e Parasitologia.
Rua Hernani Mello, 101 sala 309. Niterói, RJ, CEP 24210-130. E-mail: mipwalt@vm.uff.br 
Os resultados demonstraram que sete (5,6\%) dos 124 caprinos foram sororreativos ao AAT, sendo todos confirmados pelo 2-ME. Das três vacas presentes na propriedade, uma apresentou sororreatividade aos dois métodos diagnósticos empregados. Considerou-se que este animal, que fornecia leite para os cabritos, teria sido a mais provável fonte de infecção para os cabritos do rebanho. Mediante os resultados encontrados, os sete caprinos e a vaca sororreativa foram encaminhados para abate e o leite das vacas negativas passou a ser tratado termicamente antes de ser fornecido aos cabritos. Além disso, todos os animais adquiridos passaram a ser testados antes de entrar na propriedade. Doze meses após os primeiros testes, todos os animais do rebanho foram novamente testados e todos os animais foram negativos.

Os resultados encontrados demonstram a importância do controle da brucelose em caprinos, em especial quando criados em associação com outras espécies, como bovinos. Apesar da sororreatividade para B.melitensis em caprinos não ter sido demonstrada no Brasil (Poester et al., 2002), B.abortus ainda ocorre nos rebanhos bovinos, que podem servir como fonte de infecção para pequenos ruminantes e causar alterações reprodutivas nestes animais (Radostits et al., 2000). Estes dados não estão de acordo com alguns estudos preliminares, que não encontraram qualquer sororreatividade nos rebanhos caprinos estudados (Rogick, 1941; Brito, 1985; Alves, et al., 1997). Entretanto, os dados obtidos neste estudo

\section{Referências}

ALTON, G.G.; JONES, L.M.; ANGUS, R.D.; VERGER, J.M. Techniques for the Brucellosis Laboratory. Institute National de La Recherche Agronomique (INRA), Paris, 1988.

ALVES, C.J., VASCONCELLOS, S.A., MORAIS, Z.M., LEITE, E.A., GOMES,A.A.B. Avaliação dos níveis de aglutininas anti-Brucella em soros de caprinos de cinco centros de criação do nordeste do Brasil. Rev Bras Ci Vetv. 4, p. 89-91, 1997.

BRASIL. Instrução Normativa SDA № 06, de 08 de Janeiro de, 2004. Regulamento Técnico do Programa Nacional de Controle e Erradicação da Brucelose e Tuberculose Animal do Ministério da Agricultura Pecuária e do Abastecimento. Disponível em: http://www.agricultura.gov.br/sda/ dda/programa.htm

BRITO, D.B.; REIS, C.A.B.;FIGUEREDO, J.B. Brucelose caprina no Estado da Guanabara. Rev Med Est Guanab, v. 38, p. 208-211, 1971.

BRITO, W.M.E.D. 1985. Aspectos zoo-sanitários em caprinos de diferentes formas de exploração no sul de Goiás e Distrito Federal. Tese de Mestrado, UFMG, Belo Horizonte, 42 p.

KABAGAMBE, E.K.; ELZER, P.H.; GEAGHAN, J.P.; OPUDA-ASIBO, J.; SCHOLL, D.T.; MILLER, J.E. Risk factors for Brucella seropositivity in goat herds in eastern and western Uganda. Prev Vet Med, v. 52, p. 91108, 2001

LEAL-KLEVEZAS, D.S.; MARTINEZ-VAZQUEZ, I.O.; GARCIA-CANTU, J.; LOPEZ-MERINO, A.; MARTINEZ-SORIANO, J.P. Use of polymerase chain reaction to detect Brucella abortus Biovar 1 in infected goats. Vet Microbiol, v. 75, p. 91-97, 2000.

LILENBAUM, W.; SOUZA, G.N.; RISTOW, P.; MOREIRA, M.C.; FRÁGUAS, S.; CARDOSO, V.S.; OELEMANN, W.M.R. A serological study on reforçam os achados de outros autores nacionais que encontraram animais reativos em inquéritos sorológicos (Brito et al., 1971; Viegas et al., 1980; Silva et al., 1983). Em estudo recente, Lilenbaum et al. (2007) relataram a presença de aglutininas anti- $B$. abortus em cinco caprinos amamentados com leite bovino em uma propriedade no Rio de Janeiro. $\mathrm{Na}$ literatura internacional Ocholi et al. (2004), relataram o isolamento de B.abortus em um rebanho caprino e Kabagambe et al. (2001) que descreveram a ocorrência de infecção mista por B.abortus e B. melitensis. Segundo LealKlevezas et al. (2000), infecções por B.abortus ocorrem em diversos rebanhos caprinos, principalmente em países em desenvolvimento.

É importante ressaltar que através de testes sorológicos, não é possível distinguir entre a presença de aglutininas antiB.abortus e B.melitensis. No entanto, a partir dos aspectos epidemiológicos envolvendo a presença de bovinos sororreativos na propriedade e a ausência de B.melitensis no Brasil, os achados deste estudo sugerem fortemente tratarse de infecção por B.abortus em caprinos.

Conclui-se, portanto, que a brucelose por B.abortus ocorre em caprinos e que esta importante enfermidade requer maior atenção dos veterinários e um programa de diagnóstico e controle se faz necessário a fim de aumentar a produtividade e a sanidade dos rebanhos de caprinos no Brasil.

Brucella abortus, caprine arthritis-encephalitis virus and Leptospira in dairy goats in Rio de Janeiro, Brazil. Vet J, v. 173, p. 408-412, 2007. MEGID, J; SALGADO, V.R.; KEID, L.B.; SIQUEIRA, A.K.; MEIRELLES, C.E.; MORETTI, D.M. Infecção em cão por Brucella abortus: relato de caso. Arq. Bras. Med. Vet. Zootec, v. 59, n. 6, p. 1583-1585, 2007.

OCHOLI, R.A,; KWAGA, J.K.; AJOGI, I.; BALE, J.O. Phenotypic characterization of Brucella strains isolated from livestock in Nigeria. Vet Microbiol, v. 103, p. 47-53, 2004.

OFFICE INTERNATIONAL DES EPIZOOTIES. In: Manual of Diagnostic Tests and Vaccines for Terrestrial Animals. Disponível em <http:// www.oie.int/eng/normes/manual/A_00043.htm>.

POESTER, F.P.; PICAO, V.S.G.; LAGE, A.P. Brucellosis in Brazil. Vet Microbiol, v. 90, p. 55-62, 2002.

RADOSTITS, O.M.; GAY, C.C.; BLOOD, D.C., HINCHCLIFF, K.W. Clínica Veterinaria: Um tratado de doenças dos bovinos, ovinos, suínos, caprinos e equinos. 9. ed. London:W.B. Saunders, 2000. p. 778-791. RIBEIRO, M.G.; NARDI J.G.; MEGID, J.; PAES. A.C.; LISTONI, F.J.P. Aglutininas anti-Brucella abortus no soro e em secreção de bursite cervical em eqüinos. Arq. Bras. Med. Vet. Zootec. v.55 n.1, p.99-101, 2003.

ROGICK, F.A. Pesquisas sobre a brucelose caprina em São Paulo. Rev Ind Anim, v. 4, p. 33-37, 1941.

SILVA, M.U.D.; SILVA, E.D.F. Possíveis causas de aborto em caprinos. Comunicado técnico. Embrapa - Centro Nacional de Pesquisa de Caprinos, v. 12, p. 1-9, 1983.

VIEGAS, E.A.; VIEGAS, S.A.R.A.; CALDAS, E.M.; FARIA, A.F. Investigação sorológica para brucelose em caprinos e ovinos no Estado da Bahia. Arq EMV-UFBA, v. 5, p. 99-110, 1980. 